\title{
COLLATERAL BEAUTY \\ A DIGITAL ARTWORK OF A POET'S SPIRIT
}

\author{
By \\ Maryam Lary
}

BS Communication \& Media Sciences, Zayed University, Dubai, UAE, 2008

An (MRP)

presented to Ryerson University

in partial fulfillment of the requirements for the degree of

Master of Digital Media

in the program of

Digital Media

Toronto, Ontario, Canada, 2017

(C) Maryam Lary, 2017 


\section{Author's Declaration for Electronic Submission of a MRP}

I hereby declare that I am the sole author of this MRP. This is a true copy of the MRP, including any required final revisions. I authorize Ryerson University to lend this MRP to other institutions or individuals for the purpose of scholarly research. I further authorize Ryerson University to reproduce this MRP by photocopying or by other means, in total or in part, at the request of other institutions or individuals for the purpose of scholarly research. I understand that my MRP may be made electronically available to the public. 


\begin{abstract}
In a digital age, we try to be innovative and creative when interacting with our audience. With an interest in written poetry, I went to look for ways to present poetry in an interactive way. This paper/project explores the potential of poetry in a digital form. It explains the process of combining visual art with technology and digital sensory to communicate poetry in a new format. This paper will explain the idea behind the project, the methodology used to apply it, the materials, and the technology embedded in it.
\end{abstract}




\section{ACKNOWLEDGMENTS}

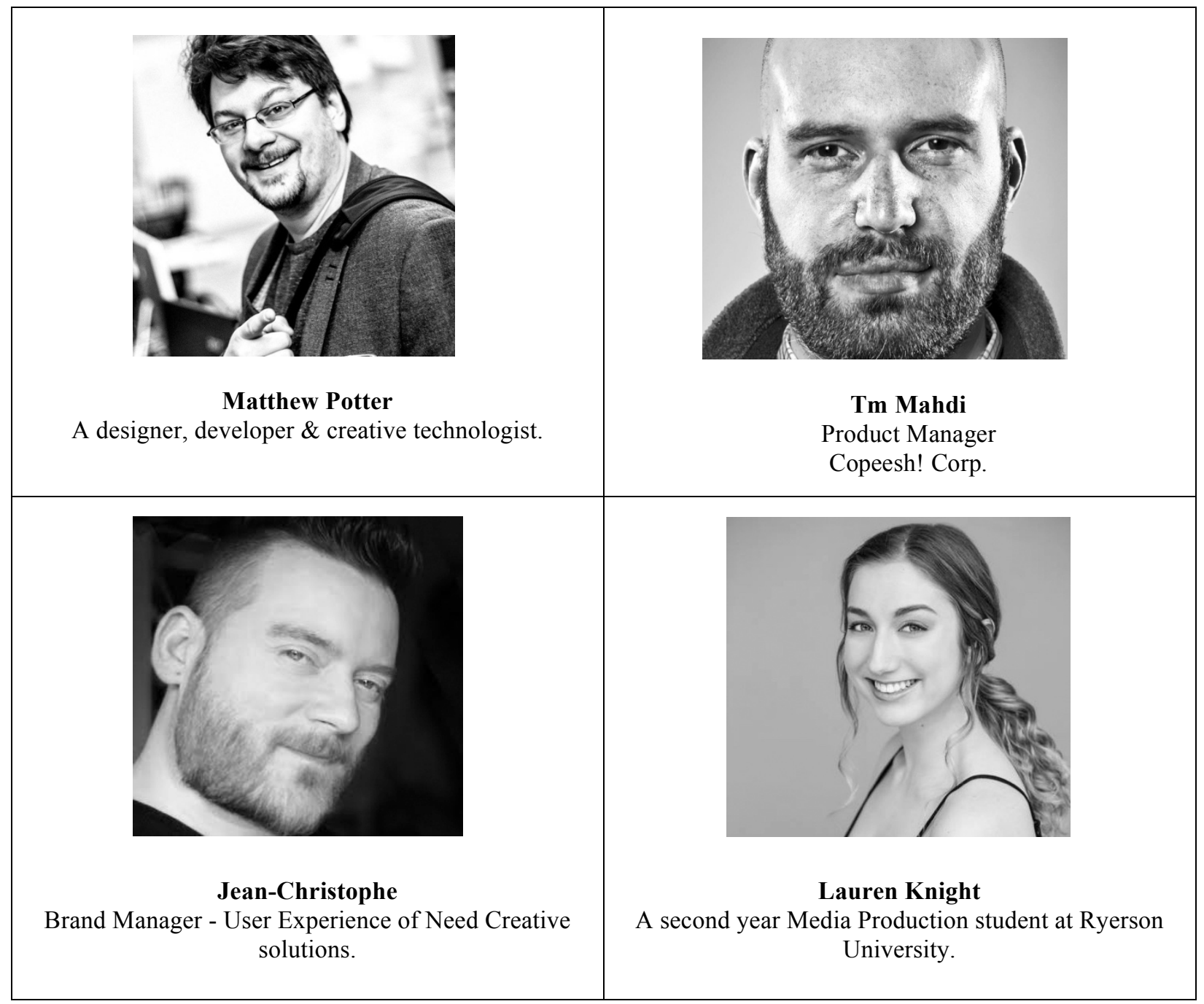




\section{TABLE OF CONTENT}

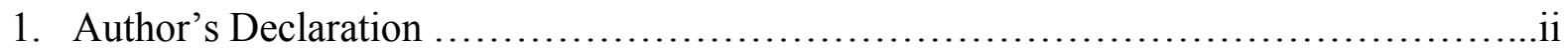

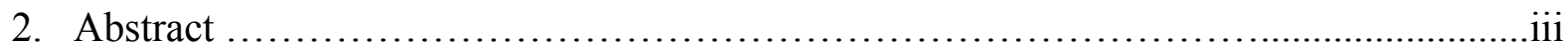

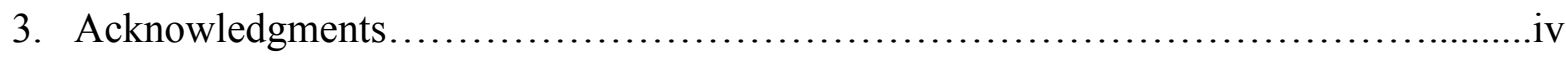

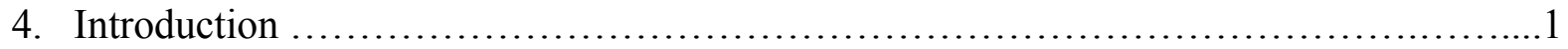

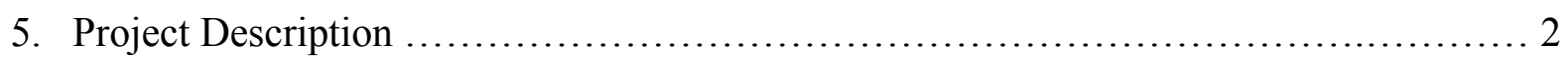

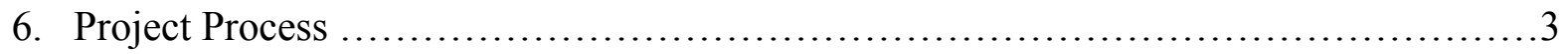

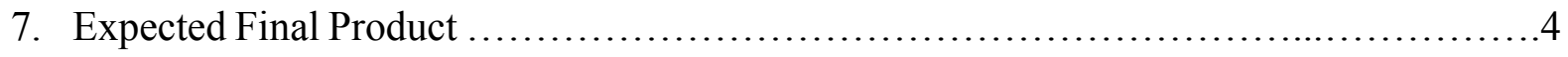

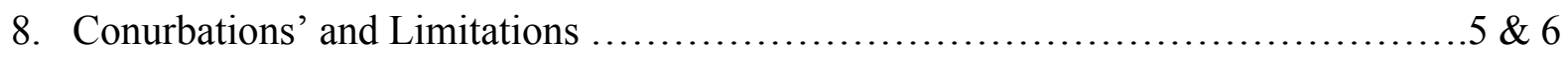

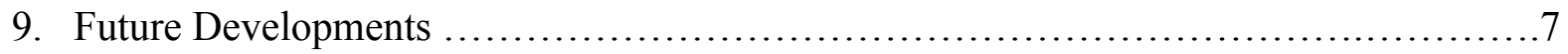

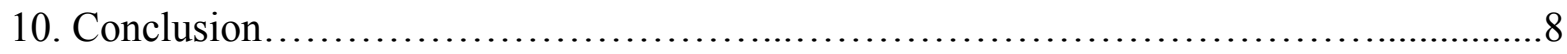

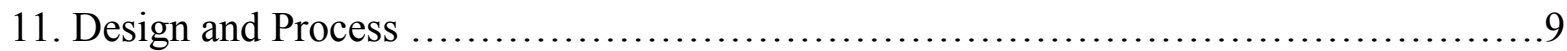

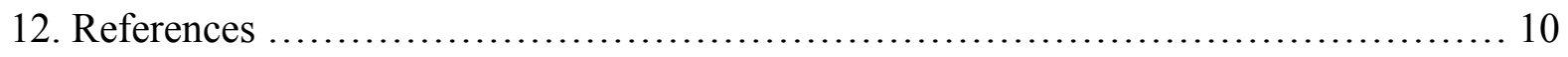




\section{INTRODUCTION}

"What is poetry?" This question is often asked, and many different views are shaped out of this question. Some say that poetry can be in a form of a song, and some argue that poetry is a very specific way of writing that expresses emotions, thoughts, and experiences by using complex words and imagery. According to The Atlantic website, poetry is defined as "The art of rhythmical composition, written or spoken, for exciting pleasure by beautiful, imaginative, or elevated thoughts." Some sources state that the term poetry comes from the Greek term, "poiesis" which means "making," and refers to a form of literature that uses artistic and rhythmic qualities of language — such as phonaesthetics, "The study of the aesthetic properties of speech sound, in particular the study of sound sequences, as in phonaesthesia." sound symbolism, and metre-to evoke meanings in addition to, or in place of, the prosaic ostensible meaning ${ }^{1}$. Or "literary work in which special intensity is given to the expression of feelings and ideas by the use of distinctive style and rhythm; poems collectively or as a genre of literature." Unlike other literary forms that we can date to exact texts and time periods, it is a challenge to pinpoint the earliest work of poetry. In one form or another, poetry has been around for thousands of years ${ }^{2}$.

\section{PROJECT DISCRIPTION}

As a writer and a poet, I wanted to explore a new way for people to experience my voice through an art piece that represents my feelings and gives the viewer an idea of what poetry entails. With digital integrations of sensors embedded in the art piece, the project's objective is to connect the audience to feelings, images, and expressions during the writing process, away from the text and traditional poetry. In this paper, I will explain the process of coming up with this idea as a start

\footnotetext{
${ }^{1}$ Mark Yakich, "What is a Poem" The Atlantic. https://owl.english.purdue.edu/owl/resource/747/01/. Accessed 23 July. 2017

${ }^{2}$ Mill, John Stuart. “What Is Poetry?” Essays on Poetry (1976): 3-22. Accessed 23 July. 2017.
} 
and how it transformed to an artwork that captures my emotions. I will explain the developments and the challenges that I experienced in the making process and the industry leaders that I have worked with to get the project to the level I wanted it to reach. The poems in this project describe "hardships and healing" and represent a process of hurt, healing, and resulting emotional growth. Each part of the physical heart should communicate a message to the person viewing the project. My vision in creating this experience for poetry comes from a realization that not all people are readers, some people prefer a visual representation of their surroundings. Therefore, I explored a new idea to combine my passion for art and drawing with my love for poetry in a digital experience, giving a chance to readers to read, and visual people to understand my poetry in a nontraditional form, giving everyone a chance the connect to my words and my feelings. This project focuses on creating an interface for poetry to be interactive and more appealing.

This project is a journey of self-discovery, the poet's emotions and words translated into a physical design. It's built to involve the audience in its expression. The viewer gets to sense the voice of the poet in its digital integrations of touch, sound, and imagery. The concept was born from my love for traditional poetry, then going a step further by creating a digital artwork that portrays, emotions of pain, self-worth, and healing in an artistic design. Each element projects an in-depth view of sensations.

The heart represents all the mixed feelings a person can go through in life, the girl in her position, illustrates fear, sadness, and confusion. However, the upper grid represents the beauty of our pain, hope, the power to heal, rise, and flourish above all the hardships of life. The concept started simple, by drawing an art visual that combines digital components of motion sensors and sound systems to represent my poetry in a new format of an interactive experience. As time progressed, it transformed into something more defined and complex. By using an artistic view to 
give my vision more of a 4D look to convey emotions. The viewer is able to touch different parts of the heart to feel poetry away from its traditional style. The project takes into consideration, the user's experience and the power of design. All the materials used are carefully chosen with love and keeping the audience in mind.

\section{PROJECT PROCESS}

The project first started as an interactive digital printed image on a canvas. With my vision and emotions, I wanted to express for this project, I looked at representations of sadness, and healing and sketched a drawing that conveys these emotions. From there I worked with Copeesh! printing services to replicate my drawing into a digital format and make sure the printed image was of a high quality. I first started by using conductive thread. Conductive thread is a thread which looks and behaves like conventional sewing thread and also conducts electricity, allowing it to be used with electronics in place of wires. It has low resistance of approximately $0.4 \mathrm{ohm} / \mathrm{cm}$ (40 ohm $/ \mathrm{m})$. It can carry current the same way that wires can, which means it can be used to create a circuit. This allows the user to sew a circuit together, it's flexible and requires no soldering ${ }^{3}$. It is best used for craft projects and fabric. Also, it's widely used in wearable technology. It's considered to be very safe and one of the easiest ways to learn how to use embedded electronics. After the image got finalized and printed, I realized that it wasn't interesting in the way it looked. The conductive thread was easy to use and the process was enjoyable, however, it had its limitations when it came to interactivity, and I realized with time that putting it on a canvas with an image is not what I wanted for my poetry because I wanted to give the project a deep artistic feel that looked as a 4D object.

\footnotetext{
3 “Conductive Thread Basics" Sparkfun. https://learn.sparkfun.com/tutorials/sewing-with-conductive-thread. Accessed 23 July. 2017.
} 
With time, I decide to go many steps further and replicate the image I have to fabric, giving depth and texture to the project. I wanted the audience to touch and feel the texture of the heart and give more to the idea than a flat image. I started looking at art projects that involve fabric and studied the process of working with fabric, from choosing the materials, to how to stick everything together, and how to come up with a clean finished look.

\section{EXPECTED FINAL PRODUCT}

As an outcome for this project, I expect an interactive piece where people get to touch and experience a voice of a poet, feel connected to the meanings behind each part and understand that poetry and expressions can transform over time and that there is always a way to take what we love to the next level. I was anticipating my heart shaped artwork to have video, and around three elements of digital interactions. However, the video element was challenging to implement without making the audience distracted by so many different components. I ended up having two digital integrations in the artwork itself and I had to put one of the sounds effects separate from the art piece. Nevertheless, the outcome of having two digital components to the project is still a success point considering the limitations and challenges the project has had during the making. From a personal point of view, I think it's not always about the outcome which we anticipated, but the lessons and developments we go through in order to make things work. I believe at this point there is a great chance for the project to grow and go beyond the expectations it had in the first place. 


\section{CONTRIBUTIONS AND LIMITATIONS}

During the process of coming up with the digitalized art work, I have had many different challenges and limitations of my own knowledge. Therefore, I reached out to industry professionals who contributed to the progress of the project and helped me gain knowledge that was helpful to me in reaching the outcome I want. At the beginning of the project, with my art direction and vision, I reached out to Copeesh! printing agency to help me digitize my sketch for the project, and support with printing materials. Tm Mahdi, Creative director of Copeesh!, took on the project working with his designer, Michael Gatioan,

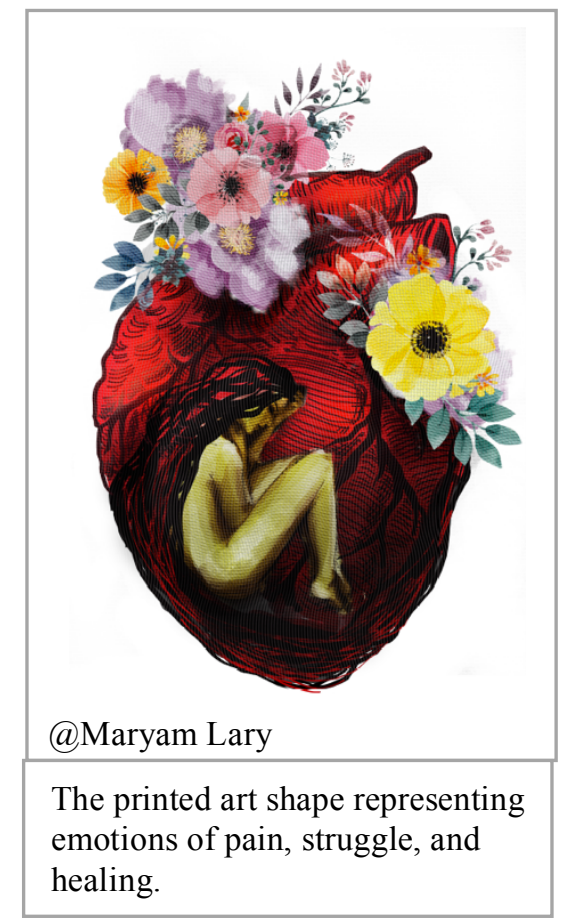
to make the vision and reality. It took lots of effort, consecutive meetings and iterations for the project to reach the expected outcome. After the image has been designed by Photoshop, it had to go to print. The complexity of this project is in its creative aspect, where we had to not only print the canvas but the layout around it, it took many trial and error to get to the right shape.

While the design aspect of the project was being prepared, I was investigating what type of sensors I needed embed in my art piece. I used the technology from BigDawgs Greetings where I get to input the sound I need in the devices. I used a motion sound sensor for the upper grid of the art work. The way a motion sensor works is that it senses movement and unromantically starts playing music. The type used for this project is an Area Reflective Type. This means that it radiates from an LED. Using the reflection of those rays, the sensor measures the distance to the person or object and detects if the object is within the designated area to switch on ${ }^{4}$.

\footnotetext{
${ }^{4}$ Shoaib, Muhammad, et al. "Fusion of smartphone motion sensors for physical activity recognition." Sensors 14.6 (2014): 10146-10176. Accessed 21 June. 2017.
} 
This allows the user to wave their hands, or even stand in front of the artwork and listen to a song which I have wrote myself in collaboration with a talent from Ryerson. Also, for the other part of the heart, I embedded a sound card where the viewer touches the part and listens to a poem. There were a lot of issues with this part because the sound output was not very loud for the space of show. Also, embedding it under cloth made the sound drop. I had to figure out a way to work with the equipment I had, from there, I connected with Matthew Potter, a seasoned designer, developer and creative technologist who specializes in graphic communication and problem solving, workflows and production processes. Matthew Potter is passionate about providing both direct one on one support to individuals and community groups. He lives his life based on a simple idea: "If I have an apple and share it with you, we only have half an apple each. If we share an idea with each other, together we have four ideas; my idea, your idea, your idea of mine, and my idea of yours." He has worked on many creative technology projects around Canada. He thought me how to solder weirs and proposed a solution on connecting the sound card to a bigger speaker that will help me get the outcome I need. Under his supervision, I was handling the whole process and testing new ways to solve my challenge. It was one of the most memorable things I learned recently. Thanks to him, I now understand more about technology and how and why things the way they do.

In the designing process of the heart and choosing the fabric, I was privileged to work with Jean-Christophe Pilaprat, Brand Manager - User Experience of Need Creative solutions. He is an award-winning user experience designer. For over 16 years he has helped startups, companies and organizations while still exploring and pushing the limits of all experiences in any mediumwhether more traditional media, like paint and sculpting; to more human exploration, with social 
experiments and engaging events; to new technologies, like augmented reality and user interaction with artificial intelligence. He has helped me in the process of choosing the right materials for the project, coming up with creative suggestions on how to improve the design and enhance the user's experience. He was constantly updated in the progress of the project, giving insights and suggesting places where materials can be bought at an affordable price. The major limitation for this project was the short battery life of the technologies embedded inside the artwork and the challenge of replacing it without effecting the piece. Also, with all efforts in enhancing the sound for the project, it reached to a level where the technology could not go beyond a certain frequency. That created a limitation for the project to be placed in a noisy area.

\section{FUTURE DEVELOPMENTS}

I believe that this project can go far and beyond what I have currently achieved. With better financial means, this project can have enhanced technology that will allow the sound to be loud and more effective. It can be an experience within itself where a person enters a room of interactive visuals and poetry. Also, it can be something that is archived in a digital space or a museum where the audience get to experience it to the fullest. 


\section{CONCLUSION}

If we were to answer a question of "What is poetry" then poetry can come in many shapes and forms, it can be visual, it can be heard, it can be touched and heart felt. This process of this project has been enjoyable, yet, challenging. I had challenges embedding the technology in the artwork and reaching the level I was aiming for the user experience. Yet, despite all the challenges, I have reached out to industry professionals and searched for solutions. As much as this project represents emotions of pain and the potential to grow, these emotions are exactly what I have been going through in the making of it. From there I learned to take small steps to grow every day, and search for solutions even in the hardest timings because nothing is impossible once we have passion and drive to explore new opportunities. 


\section{DESIGN AND PROCESS}

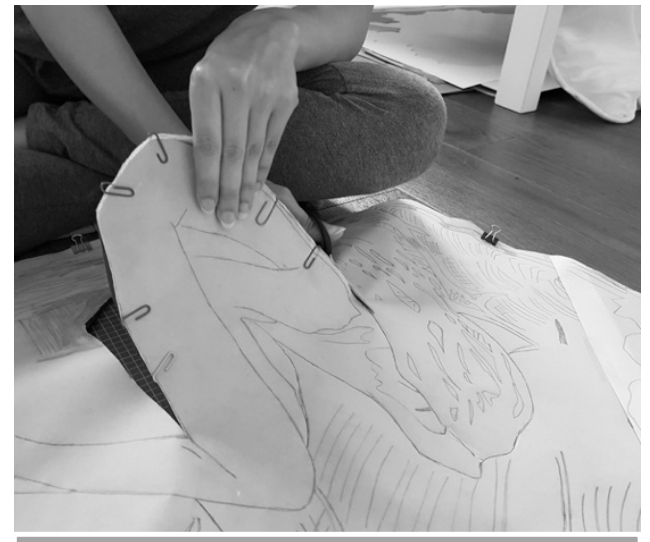

Process of replicating the design to Fabric, cutting the girl, creating depth.

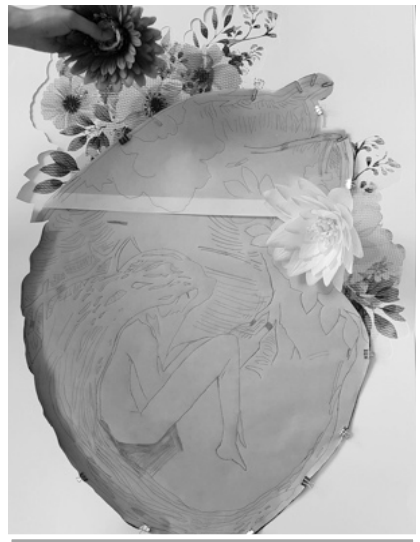

Process of replicating the design to Fabric

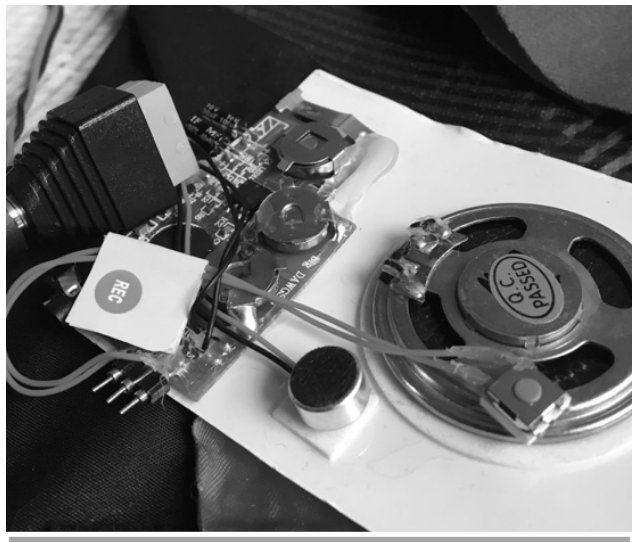

Sound Card

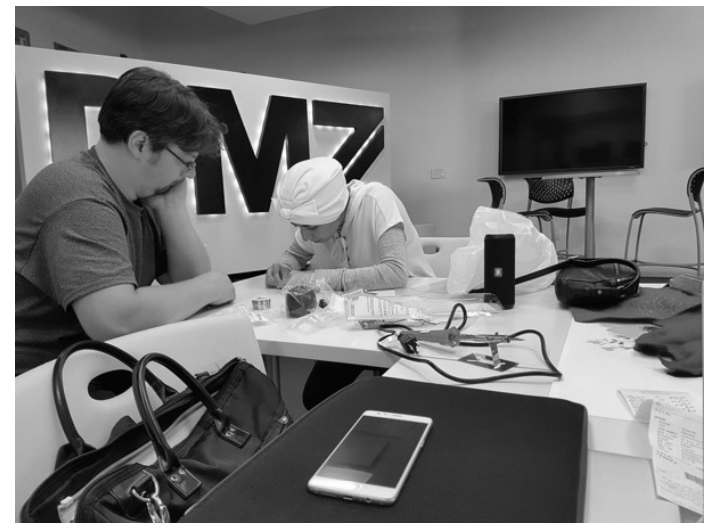

In the DMZ with Matthew Potter developing a sound system for the sound card.

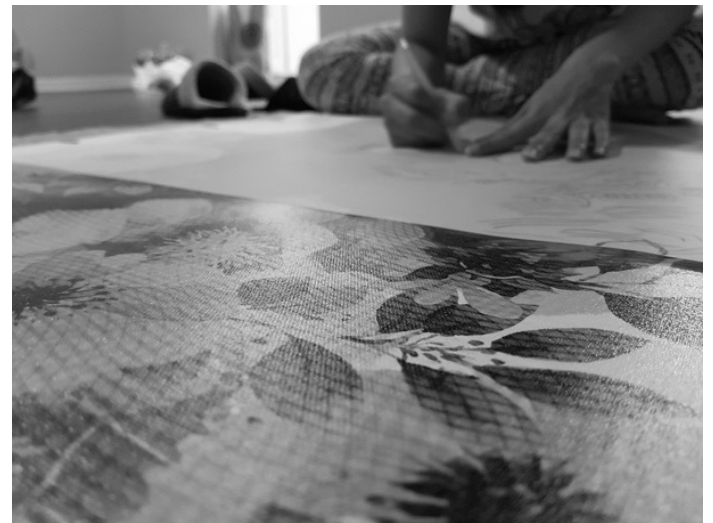

Tracing the artwork and creating the visual aspects. 


\section{REFRENCES}

"Conductive Thread Basics” Sparkfun. https://learn.sparkfun.com/tutorials/sewing-withconductive-thread. Accessed 23 July. 2017.

Mark Yakich, "What is a Poem" The Atlantic.

https://owl.english.purdue.edu/owl/resource/747/01/. Accessed 23 July. 2017.

Mill, John Stuart. "What Is Poetry?” Essays on Poetry (1976): 3-22. Accessed 23 July. 2017.

Shoaib, Muhammad, et al. "Fusion of smartphone motion sensors for physical activity recognition." Sensors 14.6 (2014): 10146-10176. Accessed 21 June. 2017. 